\title{
Percepción y construcción en la obra de Elsa Cross
}

\section{Perception and Construction in Elsa Cross' Poetry}

\author{
AlEJANDRO HIGASHI \\ Universidad Autónoma Metropolitana, Unidad Iztapalapa \\ Academia Mexicana de la Lengua \\ higa@xanum.uam.mx
}

Resumen: Pese a ser reconocida por sus méritos formales, el estudio de las estrategias compositivas que caracterizan la obra de Elsa Cross parece aplazado ante la evidencia de las temáticas religiosa y mitológica que la caracterizan. En este trabajo, analizo la transformación de las estrategias compositivas que pueden caracterizar su obra en distintos periodos, especialmente en los aspectos relacionados con la exploración estética sobre la ampliación de las fronteras de la percepción a través del Siddha Yoga.
PALABRAS Clave:

poesía mexicana;

orientalismo;

percepción;

meditación;

Siddha Yoga.
KEYWORDS:

Mexican Poetry;

Orientalism;

Perception;

Meditation;

Siddha Yoga.
ABSTRACT: Although the work of Elsa Cross has been recognized for its formal merits, the study of compositional strategies which characterize her work seems distracted by an interest in the religious and mythological themes that have characterized her poetry. In this work, I analyze the transformation of compositional strategies which can characterize her work in different periods, especially in the aspects related to her aesthetic exploration on the extension of the frontiers of perception in the Siddha Yoga. 


\section{En los márgenes de la percepción, la palabra}

La obra poética de Elsa Cross es amplia, diversa y compleja. ${ }^{1}$ De Canto malabar (1987) ha escrito Adolfo Castañón que "es el libro más acabado y maduro entre los hasta ahora publicados por la autora de La dama en la torre y, sin duda alguna, uno de los más limpios y perfectos entre los producidos por la poesía mexicana del último tercio del siglo xx" (1994: 11). David Huerta, por su parte, Ilama la atención en su prólogo a Baniano sobre la cerrada correlación entre el "talante iniciático" de esta obra y "su enorme cuidado por dar testimonio de una experiencia interior y de hacerlo con las palabras justas" (2012: 4). Octavio Paz, en una presentación a Miroir au soleil, escribió que "su obra, ya considerable, reúne algunos de los poemas más perfectos entre los escritos por las últimas generaciones mexicanas" (1996: s/p). Aunque estos tres autores coinciden en subrayar el rigor formal de su obra, la crítica académica suele limitarse a las temáticas orientalistas (por ejemplo, Dauster 1998; Pollack 2011 y, últimamente, Gutiérrez 2017). Esta concentración en el aspecto temático Ilama poderosamente la atención, en especial por ser la misma Elsa Cross quien, luego de un recuento de los y las poetas que en México han incorporado temas del lejano oriente, su propia obra incluida, reconoce que desde Tablada y Rebolledo hasta Octavio Paz, y varios miembros de su propia promoción, en esta poesía "más que una transformación en la escritura, ha habido un cambio vital que aplica a las propias circunstancias y al propio espacio mexicano, aquello que estas disciplinas han revelado" (Cross 2018: 34).

La poesía, por supuesto, es una forma. Complementariamente, el eje de estas poéticas orientalistas es la percepción intensificada de la realidad a través de los filtros de una meditación sistemática. Aunque en primera instancia la percepción no parece una forma, no podemos perder de vis-

1 Como puede comprobarse por libros como La dama de la torre (1972), publicado en la prestigiosa colección Las dos orillas, de Joaquín Mortiz y ganador del Premio Nacional de Poesía Joven, SEP; Tres poemas (1981) donde incluyó Las edades perdidas, Espejo al sol y Pasaje de fuego; Baniano (1986); Canto malabar (1987); El diván de Ántar (1990), Premio Nacional de Poesía Aguascalientes 1989; Jaguar (1991), Casuarinas (1992), Urracas (1995), Cantáridas (1999), El vino de las cosas (2004), Cuaderno de Amorgós (2007) y Bomarzo (2009). En todos los casos, tengo en cuenta las primeras ediciones, pero cito siempre por la última revisión realizada por la misma autora en su Poesía completa (Cross 2012). 
ta que toda percepción relevante (cognitivamente hablando) termina por desembocar también en una forma. Como apunta José E. García-Albea desde la psicología cognitiva, para que la percepción sensorial se vuelva conocimiento, primero se debe realizar una selección de los estímulos relevantes del conjunto de transacciones físicas entre los organismos vivos y el medio (una transducción funcional dirigida por un foco atencional) y después, someter estos datos todavía físicos y no simbólicos a un tratamiento informativo que los convierta en representaciones simbólicas (1999: 193-194). Para el mismo García-Albea, lo que percibimos directamente de nuestro medio a través de los cincos sentidos en realidad "no sería ya el resultado de una captación directa sino de procesos de inferencia (de cómputo interno, categorización, etcétera)" (195).

En la poesía de Elsa Cross, la forma no puede desligarse de su intención general. Como apunta Castañón, "la plenitud de Elsa Cross es la de un lenguaje, de un conjunto de recursos imaginarios y, al mismo tiempo, la de una sintaxis que sabe hacer pasar desapercibidas y prestar un aire espontáneo a materias y formas no exentas de la mayor complejidad" (1994: 11). La misma Cross lo advierte al inicio de su compilación hasta ahora más abarcadora, su Poesía completa, donde afirma: "al ver en retrospectiva todo este trabajo, me doy cuenta de que es unitario en aspectos formales, así como en su búsqueda subyacente de un sentido profundo de la poesía. No hay cambios bruscos de voz ni hay estridencias. Hay, acaso, un refinamiento progresivo" (2012: 11).

El que la crítica no repare con más frecuencia en su genealogía formal quizá esté justificado por la propia relación paradójica de la poética de Elsa Cross con el lenguaje. Heredera de las corrientes contraculturales de la década de 1960, naturalmente sus búsquedas se orientaron fuera del logos racionalista. En parte, por una búsqueda personal, aunque resulta inevitable considerar el contexto de su primera educación sentimental; como ha apuntado Angélica Tornero:

La generación a la que pertenece Elsa Cross vivió los agitados cambios de la década de 1960, aún en plena juventud. Los artistas y escritores jóvenes de la época se adherían a los movimientos en boga, iniciados en Estados Unidos, primero por la Beat Generation y luego por los hippies, y por los movimientos 
estudiantiles, intelectuales y artísticos europeos, marcados por los pensamientos de Nietzsche, Marx, Freud y por el existencialismo. Como se sabe, la generación beat se introdujo de manera definitiva en la filosofía oriental, lo que trazó un espíritu de época. [...] Los poetas y artistas practicaron la meditación y defendieron la liberación espiritual y sexual. Algunos integrantes de estas generaciones occidentalizaron los valores de las religiones orientales, cosa que Elsa Cross no hizo. Aunque pertenece a esta generación, la poeta siguió un derrotero diferente, con algunos puntos de coincidencia. Su adhesión al clasicismo — vía los mitos - y, sobre todo, la comprensión de la tragedia a partir del pensamiento de Nietzsche le permitieron relacionarse con los valores de la juventud de esa época, centrados en la liberación de las ataduras del logos occidental (Tornero 2015: 201-202).

Aunque el mundo antiguo fue un tópico persistente desde sus primeras obras (Tornero 2015: 198), en el plano de la construcción literaria puede advertirse por el contrario una búsqueda de distintas tesituras. En Naxos, de 1966, Elsa Cross se ejercitó en el poema en prosa (al que, por cierto, nunca volvió); en Verano, inédito en su momento (ahora en su Poesía completa), apostó por el verso de arte menor y el poema breve; en Herencia los poemas crecen en extensión y el verso de arte menor da paso en varias ocasiones al versículo; Amor el más oscuro es su primer poema extenso, dividido en cantos (estructura que identificará buena parte de su producción posterior). Estas búsquedas formales coincidirán en su primer poemario importante, La dama de la torre (1972), Premio Nacional de Poesía Joven, sEP. Como señala la misma Cross, este último libro "marcó el final de un periodo de varios años de escritura" al que siguió un lapso de nueve años durante el cual destruyó dos libros, hasta la publicación de Tres poemas (1981) y Bacantes (1982) (Vázquez Valdez 2004: 28).

El resultado es asombroso: Tres poemas (1981) contiene ya todas las formas que serán características en la obra de Cross, desde el uso del verso partido hasta el poema extenso dividido en cantos. Su unidad formal será saludada con admiración por Marco Antonio Campos, quien dirá que los tres libros incluidos aquí le parecieron, "salvo leves diferencias, unitarios en su trazo, lenguaje y tono" (1981: 58). Resulta difícil, si no imposible, identificar la plétora de influencias literarias (y no literarias) a las que esta- 
ría expuesta una poeta joven por esos años, pero quizá convenga especular, porque en varios poemas de esta época pueden advertirse muchas de las claves que sostendrán su trabajo poético posterior. Ya en un poema tan temprano como Pasaje de fuego, por ejemplo, datado entre 1975 y 1977 en su Poesía completa, se reconoce una voz que emerge igual de la meditación que de lo más profundo del sueño y que renuncia al lenguaje del logos occidental como forma de expresión; lo primero que se pierde en esta purga son las palabras, enmudecidas en favor de una intensificación de las impresiones provenientes de los sentidos (principalmente estímulos visuales como el "reflejo", "el filo de la espada", el "ala multicolor" o auditivos como "el zumbido" y "la voz" ), y descartadas una a una "como cuentas un collar que se desgrana":

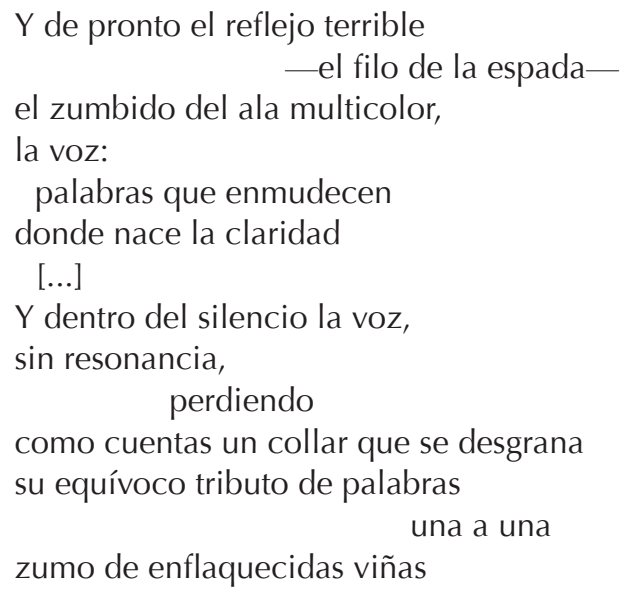
(2012: 185).

(2012: 187).

De esta purga nacerá un nuevo lenguaje que recuerda en sus imágenes el estilo lacónico de los sustantivos abstractos y, en sus formas, la particular configuración estrófica de Blanco, de Octavio Paz (1990: 479-496), pero al que Cross sumará un plano espiritualista. Aquí, la voz de luz recién recobrada dará paso a una conciencia que "asciende custodiada por las alas de fuego / desde su pozo de infortunio / prisión / cisterna seca" (2012: 192). En estos primeros libros, el estilo de Elsa Cross se mimetiza con su intención de plasmar el proceso de una percepción más extensa y pro- 
funda a través de un lenguaje abstracto y con una fuerte tendencia a la yuxtaposición.

Durante los años que median entre La dama en la torre y Tres poemas, en agosto de 1976, Elsa Cross descubrió la meditación (la voz de luz que aparece persistentemente en Pasaje de fuego) a través de Swami Muktananda y conoció a Octavio Paz (Vázquez Valdez 2004: 30). En 1978, en vísperas de su primer viaje a la India, Paz escribió a algunos amigos suyos allá para que ella no estuviera sola (Cross 2015b). Aunque en principio parece una casualidad, lo cierto es que la coincidencia de una nueva forma de percibir el mundo (la meditación) y de una nueva forma de escritura (la de Blanco) crea un vínculo natural y solidario que la misma Cross explicaría con posterioridad a propósito de Blanco:

Paz comparte, con muchas visiones orientales, la intuición de que no sólo el universo, sino todo aspecto de la realidad surge, se sostiene, se destruye y vuelve a surgir. La realidad es anadi y anānta. Fin y comienzo no existen, o están en todas partes. La esencia de la realidad, la eternidad, etcétera, no se encontrarán al final de los tiempos, sino aquí y ahora. Estos paradigmas son mucho más cercanos a la visión de Paz que los de las concepciones tradicionales de Occidente.

[...]

Un cambio de visión del mundo desde luego se refleja en el manejo del lenguaje, ¿o podría ser quizá su resultado? Realidades múltiples que toman forma en imágenes paralelas o correspondientes, espacios abiertos, pausas, silencios dentro del texto, lo vuelven ese texto que permite varias lecturas simultáneas donde apenas se tocan los muchos tiempos y espacios que confluyen en el decurso del poema (Cross 2014: 22-23).

Elsa Cross había leído "Piedra de Sol desde los patios del colegio", varias veces, e incluso había memorizada estrofas enteras de las hojas mimeografiadas que habían repartido en La Casa del Lago para seguir una lectura del grupo de Poesía en Voz Alta (2015a). Desde esos días, recuerda el poema de Paz "no tanto como un tema literario sino como una experiencia interna" en la que podía percibir "reverberaciones, transparencias, estallidos de luz, formas que se transmutan, que fulguran y se disuelven, que pasan y al mismo tiempo permanecen" (2015a). 
En Pasaje de fuego quizá como en ningún otro poema posterior de Cross, se revela el influjo formal de Blanco en distintas estrategias compositivas como resultado de un cambio de visión de mundo y una necesidad expresiva compleja, donde las realidades múltiples y simultáneas percibidas a través de la meditación necesitaban expresarse en un lenguaje poético que no limitara esta nueva percepción al terreno de lo conocido y contribuyera, por el contrario, a su expansión. Escribirá Cross que en estos años "era como estar desprendidos de todo y al mismo tiempo asentados en el corazón de la realidad" (2015b). En todo caso, el estilo poético del Paz de Blanco y otros poemas experimentales se mostraba cercano al estado de iluminación que Cross descubría y aunque Paz no tuvo ningún guía que lo orientara en los caminos de la meditación, Cross pensaba que desde El arco y la lira

está ocurriendo una asimilación tácita y temprana, no de ideas o conceptos de la filosofía oriental — tanto india como china—, sino de modos de pensar, de estructuras de pensamiento tremendamente móviles y flexibles, donde la visión amplia de lo circular y de lo simultáneo, del juego sutil de correspondencias entre las cosas, deja atrás el pesado mecanismo lineal, bidimensional, que con frecuencia sofoca en Occidente sistemas enteros de pensamiento bajo el peso de metodologías estériles (Cross 2015b).

Para Elsa Cross, fue la oportunidad de traducir a una forma específica los resultados de la experiencia del Siddha Yoga aprendido de su gurú, Swami Muktananda, quien en uno de sus primeros libros, una autobiografía centrada en su evolución por los caminos de la meditación, Play of Consciousness (1978), expresa estas mismas conexiones complejas: "the senses of perception and the organs of action are all able to function because of prāna"2 (2000: 33); este prāna sería el espíritu del universo y su conexión garantizaría una percepción extendida de la realidad:

Now in meditation I felt bliss and also a growing energy. [...] I would feel waves of ecstasy welling up inside me. But even though I was completely carried away,

2 "Los sentidos de la percepción y los órganos de la acción están listos para funcionar gracias al prāna" (ésta y todas las traducciones consignadas en este artículo son del autor). 
I understood everything that was happening to me, and my understanding has not changed in the least today. It is as it was then. Such understanding is very important. Sometimes I felt that my ability to understand was also new, because I remembered even the tiniest details of my experiences. I remained very attentive and tried to understand this power of intuitive intelligence ${ }^{3}$ (2000: 147).

Con una intención pedagógica, Muktananda recogerá estas experiencias a través de un registro minucioso de esta percepción extendida, que parte de lo sensorial para culminar en lo omnisciente no expresable en palabras, descrito nada más como una intensa luz:

Next I saw a light that was different from de red, white, black, and blue lights, and as it came into view, I saw many, many worlds within it. It was a soft saffron color, and in the middle of it were thousands of soft blue sparks and a soft golden radiance. It was very sweet and lovely. It arose within the series of four lights that I have already experienced. I saw many clairvoyant visions in this new light, so I watched it with great attention. Just as I had habitually passed into Tandraloka in meditation, so I now entered the place within the radiant light. I shall call it Sarvajnaloka, the world of omniscience ${ }^{4}$ (2000: 160).

En el canto VIII de Pasaje de fuego, por ejemplo, Cross recurre al verso partido de arte menor, en ocasiones ocupado sólo por una palabra, para sugerir distintos recorridos de lectura a partir de la escisión. La disposición escalonada de sintagmas breves yuxtapuestos fue una forma de mimetizar el estilo con la experiencia perceptiva que se intentaba reflejar. La ruptura

3 “Durante la meditación sentí felicidad y también una energía creciente. [...] Sentía oleadas de éxtasis brotando dentro de mí. Pero a pesar de que me dejé llevar por completo, entendí todo lo que me estaba sucediendo y mi comprensión no ha cambiado en lo más mínimo hoy. Es como era entonces. Tal comprensión es muy importante. A veces sentía que mi capacidad de comprensión también era nueva, porque recordaba incluso los detalles más pequeños de mis experiencias. Permanecí muy atento e intenté comprender este poder de la inteligencia intuitiva".

4 "Inmediatamente vi una luz que era diferente de las luces rojas, blancas, negras y azules, y cuando apareció, vi muchos, muchos mundos dentro de ella. Era un suave color azafrán, y en el medio había miles de sutiles chispas azules y un suave resplandor dorado. Fue muy dulce y encantador. Surgió dentro de la serie de cuatro luces que ya he experimentado. Vi muchas visiones clarividentes en esta nueva luz, así que lo vi con gran atención. Tal como había pasado habitualmente en Tandraloka en meditación, ahora entré en el lugar bajo la luz radiante. Lo Ilamaré Sarvajnaloka, el mundo de la omnisciencia". 
de un discurso sucesivo y causal sugería naturalmente una percepción agudizada por la meditación y ajena al lenguaje (cuya principal limitante precisamente consiste en presentarse organizado en secuencias sintácticas lineales):

$\begin{array}{ll}\begin{array}{ll}\text { Mirada que pierde } \\ \text { Soledad }\end{array} & \text { en el agua } \\ \text { deja en su sueño } & \text { reflejo turbado } \\ \text { Súrculos concéntricos } & \text { boje de humo los espejos } \\ \text { borra las sombras } & \text { las luces del sol } \\ \text { en las estatuas } & \text { El otro } \\ \text { el doble, yo } & \text { el que pregunta, yo } \\ \text { responder } & \text { bufón de Dios } \\ \text { muchacha mendicante } & \text { busca su tumba } \\ \text { Profecía hincada } & \text { en el desierto } \\ \text { Llama viva } & \text { en el agua } \\ \begin{array}{ll}\text { Pacta con insectos } & \text { habla con los muertos } \\ \text { finge la voz del viento } & \text { ulula, calla } \\ \text { Dormir dormir } & \text { despertar }\end{array}\end{array}$

(Cross 2012: 188-189).

Además de coincidir con Paz en temas como el del doble o el de los círculos concéntricos, se advierte una confluencia en la intención de construir un lenguaje dislocado meramente alusivo de la experiencia; ya no es el lenguaje de un logos lineal y ordenado, sino uno disruptivo donde el 
significado, la causalidad y el espacio son categorías flexibles que se revelan en los sintagmas yuxtapuestos del significante. Las imágenes elegidas (el reflejo, el espejo, la sombra, las luces del sol, las estatuas) subrayan el efecto deformante del lenguaje sobre la misma percepción, hasta llegar a ese yo que sólo puede percibirse como un otro. La desvinculación que sugieren los versos partidos y la yuxtaposición rompe con la noción secuencial de tiempo, contra nuestros hábitos occidentales, donde "el interés se halla en determinar el umbral que permite diferenciar lo simultáneo de lo sucesivo" (Estaún Ferrer 1999: 584), en consonancia con los estados perceptivos extendidos durante la meditación. ${ }^{5}$

En el poema de Paz, pese a todo, la forma estaba atada a un principio racional estricto (da cuenta de ello la explicación de los distintos recorridos de lectura en esa especie de prólogo que acompañó al poema); como ha escrito Hugo J. Verani, se trató de "una aventura literaria sobre la validez del lenguaje como vehículo de conocimiento" (2013: 123). El poema de Cross, en un sentido muy distinto, pretendía ser testimonio de una experiencia vital, el resultado - dice- de una "etapa muy larga y muy difícil [...], con experiencias muy intensas, algunas de las cuales están descritas en Pasaje de fuego. Es un descenso real a un infierno. Me llevó mucho tiempo empezar a entender algo acerca de la experiencia en sí misma, y de cómo se transformaría en poesía a través de símbolos que estaban muy lejos del alcance de mi mente" (Vázquez Valdez 2004: 29).

Lo más importante en el poema de Cross no es el componente lingüístico en sí mismo, sino su capacidad para encontrar en la suspensión de ciertas convenciones lingüísticas una forma idónea que se mimetiza con la intensificación de las impresiones provenientes de los sentidos durante la meditación que la autora desea proyectar. Ahí, los vacíos determinan una cadencia de mantra y sugieren el ritmo vivo del mundo; la división en

5 Swami Muktananda cita un poema de Tukaram Maharaj donde el autor declaraba que durante sus meditaciones más profundas "my sense of difference regarding space, time, and substance totally disappeared. There is no space, no time, no substance; there is no diversity. My Self appeared as the universe, and the universe, which we call objective reality, appeared as my Self" ["mi sentido de diferencia con respecto al espacio, el tiempo y la sustancia desapareció por completo. No hay espacio, no hay tiempo, no hay sustancia; no hay diversidad. Mi Ser apareció como el universo, y el universo, que Ilamamos realidad objetiva, apareció como mi Ser"] (2000: 129). 
dos columnas permite encontrar una reverberación constante entre una y otra, desde los opuestos complementarios hasta los solidarios, de la que resulta un nuevo significado sin significante (borra los espejos y borra las sombras; aparecen el otro, el doble, yo, el que pregunta; al mismo tiempo es profecía hincada en el desierto y llama viva en el agua); donde el mismo lenguaje produce la sensación de circularidad y simultaneidad ("Mirada que pierde / en el agua [...] Llama viva / en el agua"). Todo ello, como un registro mimético de un estado de agudeza perceptual.

Las coincidencias entre la obra de una joven Elsa Cross y un poeta como Paz en toda su potencia creativa no podían ser absolutas. Blanco concluye, como recuerda Hugo Verani, "reducido a una sola columna, en un espacio que se desvanece" y "el texto se vuelve sobre sí mismo como si no existiera una realidad exterior y todo fuera un peregrinaje por el lenguaje" (2013: 126). Pasaje de fuego termina, por el contrario, con una voz de luz que afirma su existencia como una nueva conciencia de ser, una omnisciencia liberada de sus dimensiones espacial ("El día / —transcurre en otro espacio-", "rompe los vientos cardinales") y temporal ("la cifrada anulación del tiempo", "traspasando los átomos del tiempo / hasta el origen"), del lenguaje racional ("grito en medio de la noche", "sonidos dispersos [...] desintegran partículas mudas") y, de forma general, como una purga absoluta donde nuestras principales categorías de control de la realidad (tiempo, espacio, logos) dejan de ser predominantes para ceder su sitio a la percepción del ser que simplemente es, que sencillamente se manifiesta a través del brillo de su desnuda existencia en círculos concéntricos (especialmente explícita en la secuencia final "sílaba ardiente / semilla / diamante / grieta de luz" que puede incluso leerse en un sentido circular sin término):

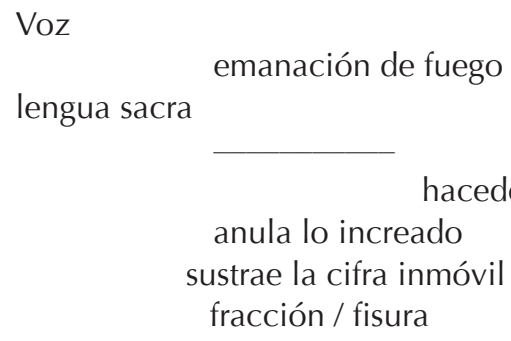




\author{
imantación del oro \\ sílaba ardiente \\ semilla \\ diamante \\ grieta de luz \\ Corona tocada por el rayo
}

(Cross 2012: 193).

Esta imagen recupera la forma en la que Elsa Cross concibe la meditación como un momento de iluminación ("grieta de luz"), un estado agudo de percepción de su presente, ajeno por completo al lenguaje (la "sílaba ardiente" ilumina y quema, pero no es lenguaje organizado), espontáneo, simultáneo, momentáneo y poderoso como "corona tocada por el rayo", formas consistentes con el Siddha Yoga aprendido de Swami Muktananda. Como apuntará éste en dos aforismos sucesivos de su colección Mukteshwari, publicado en 1969, pero traducido muy rápido al inglés, en 1972:

Understanding is eye, understanding is light.

Without it a man is worthless.

Muktananda, acquire inner understanding.

There is nothing greater ${ }^{6}$

(1995: núm. 372).

Obtain inner knowledge.

It is infinitely precious.

Muktananda, meditation culminates

in knowledge ${ }^{7}$

(1995: núm. 372).

La disposición de los significantes del poema hace consciente a quien lee de una percepción intensificada de una manera muy inmediata e intuitiva. No se trata de entender el fenómeno desde el punto de vista racional,

6 "La comprensión mira, / la comprensión ilumina. / Sin ella, un hombre no tiene valor. / Muktananda, compréndete a ti mismo. / No hay nada mejor".

7 "Obtener conocimiento interior. / Es infinitamente precioso. / Muktananda, la meditación culmina / en conocimiento". 
sino de ponerlo simplemente delante de sus ojos; como apunta Cross, la meditación:

[...] no te hace sentir tanto en un "ir hacia", sino un "estar en". No es que algún día vas a llegar a la luz, al final de no sé qué camino largo y tortuoso, sino la experiencia que te da es que ya estás ahí, tanto como quieras darte cuenta. Es una cuestión de tomar conciencia y sostenerte en ello (Vázquez Valdez 2004: 30).

Durante esta etapa, domina la intención de que las experiencias perceptivas se mimeticen con sus medios expresivos. En Bacantes (1982), los estímulos perceptivos independientes, algo rizomáticos, se suceden e intensifican. En la siguiente secuencia, del rayo pasa a la danza entre cenizas, luego a la mutación del yo en ceniza, a su aniquilamiento, a su transformación en caña hueca, río, ala, hilo de azogue y hálito:

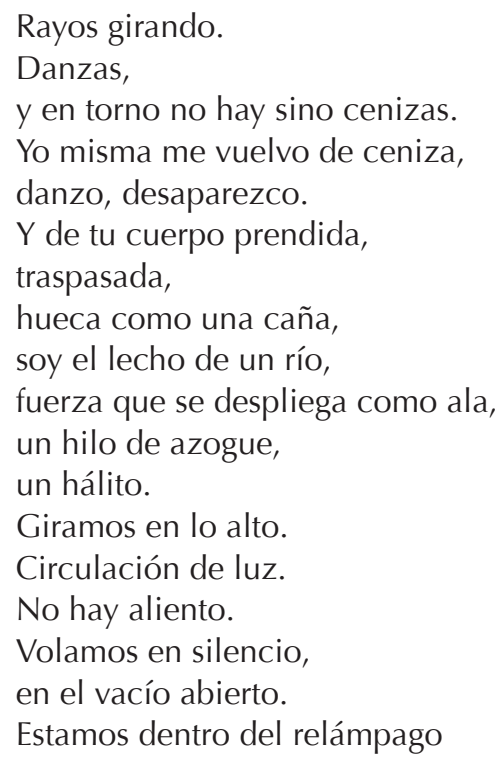

(Cross 2012: 210).

El efecto multiplicativo de estos estímulos y su coincidencia en el plano de lo simultáneo se logra por la formación de paradigmas sintácticos ("danzo, desaparezco"; "prendida, / traspasada, / hueca"; "soy el lecho 
[...], fuerza [...], un hilo [...], un hálito"; "giramos / volamos") o semánticos ("rayos girando / giramos en lo alto / circulación de luz / estamos dentro del relámpago"). Se trata, en el fondo, de listados acumulativos de estímulos poéticos yuxtapuestos que sugieren, incluso desde su misma percepción visual o auditiva, la totalidad de la experiencia espiritual.

Esta búsqueda en el plano de la construcción lingüística condujo, claro, a una reflexión recurrente dentro del mismo poema sobre la incapacidad del lenguaje. La idea ya venía desde la psicodelia y puede documentarse en una etapa previa a la exploración de Cross en la meditación y las religiones orientales (Vázquez Valdez 2004: 27-28). En Doors of Perception (1954, traducido por Editorial Sudamericana en 1956), Aldous Huxley había ya insistido en los límites conceptuales del lenguaje:

Lo que, en el lenguaje de la religión, se llama "este mundo" es el universo del conocimiento reducido, expresado y, por decirlo así, petrificado por el lenguaje. Los diversos "otros mundos" con los que los seres humanos entran de modo errátil en contacto, son otros tantos elementos de la totalidad del conocimiento perteneciente a la Inteligencia Libre (2018: 27).

Más adelante, Huxley mismo animaba a usar el lenguaje para testificar esta experiencia (él lo hace magistralmente cuando narra con detalle el resultado de la ingesta de mezcalina), pero advierte muy bien de hacerlo sin limitar la percepción de un universo ilimitado al mundo limitado del lenguaje:

Debemos aprender a manejar con eficacia las palabras, pero, al mismo tiempo, debemos preservar, y en caso necesario, intensificar nuestra capacidad para mirar al mundo directamente y no a través del medio semiopaco de los conceptos, que deforma cualquier hecho determinado dándole el aspecto demasiado conocido de algún marbete genérico o alguna abstracción explicativa (2018: 88).

Ya desde Naxos, su primera plaquette de 1966, Elsa Cross había expresado que "son a veces mis palabras como un río que perdiera su cauce" (2012: 16). Más tarde, en "La dama de la torre" publicada en la Revista de Bellas Artes en 1970, entrevió los límites denotativos del lenguaje como mero espejismo del no-decir que conduce naturalmente a la malinterpretación (las palabras no-dicen que un punto luminoso es también oscuro 
y no-dicen que un paisaje de rosas y violetas se pudrirá con el paso del tiempo); las palabras, en suma, nos entregan una percepción errónea de la realidad o, al menos, momentánea y parcial:

Salgan las palabras que no son más que palabras.

Salgan a formar espejismos solamente,

a no decir lo que las sombras son,

a no decir que un punto luminoso

puede ser también un punto oscuro,

a no decir que es putrefacto

un paisaje de rosas y violetas,

a no decir lo que es perder la luz,

caer de lo más alto

a un foso de escorpiones.

Quién cantará al amor de nuevo.

No es decir nada

decir que el corazón se rompe

(Cross 2012: 66-67).

Hacia la conclusión del poema, afirmará: "Faltan palabras, aún no he dicho nada" (69). La mejor opción para expresar este acto momentáneo de amor para el que las palabras resultan claramente insuficientes y la palabra exacta es la interrupción sugerida más adelante por los puntos suspensivos:

¿Cuál era el nombre de ese día,

el nombre de aquellas hojas en forma de corazón,

el corazón que se...

que no se...

(2012: 69).

La palabra se manifestaría desde sus orígenes como inapropiada; escribirá en uno de los poemas de "Nigredo", "No tengo mejor palabra que decir. / No es el lenguaje justo", para terminar con una imagen en la que identidad e incapacidad expresiva son dos caras de la misma moneda: "Soy un alfiler con la punta torcida" (2012: 81); también en "Nigredo" queda constancia de un lenguaje interior y poderoso refractario a las palabras —_Creció en el alma / una voz tensa y sin palabras" (76) — cuya principal 
virtud es conducir a la iluminación - "Huyen las palabras de tu mente. / Todo cede a la luz" (82)—. En Pasaje de fuego (1981), el lenguaje racional estorba más de lo que ayuda — "En el timbre agudo del silencio / a punto de romperse / —las palabras" (172)—, la palabra es sonora pero inútil - "Una frase al azar. / Ruido de címbalos" (184) - y al cierre del canto VII, el lenguaje racional sobra donde prevalece la conciencia — "palabras que enmudecen / donde nace la claridad" (185)—. Su formulación más madura de la limitada capacidad comunicativa de las palabras estará, por supuesto, en Baniano (1986):

PALABRAS

Morada oscura del sentido, prisión y límite de lo que en el silencio se nos da. Ah, palabras, que puedan todavía hilvanar tu imagen por ellas dispersada.

En vano sus fuerzas reconcilian, pues no salvan el salto que va del habla y del pensar al ser ensimismado.

al pensamiento

Vienen solas y dicen de la "cámara blanca"

(Cross 2012: 240-241).

Huxley estaba convencido del segundo lugar del arte; entre la forma en la que había percibido sin límites las patas de una silla durante la ingestión de mezcalina y la silla pintada por Van Gogh, afirmaba que "la silla de su cuadro no pasa de ser un símbolo desusadamente expresivo del hecho. [...] Pero esto es todo" (2018: 33); Muktananda, por su parte, también apuntará que la búsqueda del sentido del ser en el arte conduce a la decepción - "Looking for beauty, you lose your own beauty and become ugly"8 (2000: 9)—. El tratamiento que da Elsa Cross a estos temas, en todo

8 "Cuando buscas la belleza externa, pierdes tu propia belleza y te vuelves feo". 
caso, estuvo más en consonancia con el camino del Siddha Yoga, donde Swami Muktananda plasmó su experiencia sin reparar en los límites del lenguaje,${ }^{9}$ igual en textos biográficos de una sencillez extraordinaria como Play of Consciousness — donde, además de que la poesía aparece citada con profusión, ${ }^{10}$ se trata de una obra que, según el mismo Muktananda (2000: 211), fue inspirada por dos versos de Jnaneshwar-que en obras expresamente literarias, como los aforismos del Mukteshwari; aquí, dejará claro que la unión con una conciencia divina (the Self o Ātman) se da a través de la poesía verdadera, más allá de los libros:

Through the verses of true poets, in the mantras of the Upanishads, speaks the ecstasy of the Self. Inner knowledge is greater than the knowledge that comes from books ${ }^{11}$

(1995: núm. 380).

En una serie de entrevistas realizadas durante dos viajes de Muktananda por Estados Unidos, Europa y Australia (entre 1974-1976 y 1978-1981), dedicará dos capítulos para subrayar la centralidad del canto y los mantras en la meditación (1994:143-192) y llegará a afirmar, entre otras ideas, que "chanting makes the pure supremely pure"12 (148).

9 Abre la segunda sección de su Play of Consciousness, por ejemplo, con la siguiente declaración: "Generally speaking, one should keep secret the divine experiences with which one is blessed by God, but here I want to describe some of them for the benefit of seekers" ["Hablando en general, uno debe mantener en secreto las experiencias divinas con las cuales uno es bendecido por Dios, pero aquí quiero describir algunas de ellas en beneficio de mis seguidores"] (2000: 71).

10 Aquí acepta que muchos hombres santos "have described these experiences in their poetry but in veiled language" ["han descrito estas experiencias en su poesía, pero en un lenguaje velado"] y que "the words of these perfected sages and seers are completed and true visions of God for mankind" ["las palabras de estos sabios y videntes perfeccionados son visiones completas y verdaderas de Dios para la humanidad"]; en resumen, "they have discovered the Truth and have written about it" ["han descubierto la Verdad y han escrito sobre ella"] (2000: 93).

11 "A través de los versos de verdaderos poetas, / en los mantras de los Upanishads, / habla el éxtasis del Ser. / El conocimiento interno es mayor / que el conocimiento que proviene de los libros".

12 "Cantar hace que lo puro se vuelva supremamente puro". 


\section{En los márgenes de la palabra, la percepción}

El giro personal hacia la meditación en Baniano (1986) es de sobra conocido por el prólogo que solidariamente ha acompañado esos poemas a través de sus distintas ediciones (Cross 2012: 215-217) y está vinculado, desde su misma escritura, al conocimiento del Siddha Yoga durante el viaje que realizó Elsa Cross a la India en 1978 y que cierra simbólicamente en 1982, cuando al mostrarle el libro a Swami Muktananda, discípulo del santo Bhagaván Nityananda —el niño de Visiones del niño Râm, 2004-, le preguntó si lo había escrito a la sombra del baniano; Cross reconoció que no, que "era sólo una imagen frecuente en el libro" y Muktananda murió unos días después. La pregunta de Muktananda no era desinteresada: él solía meditar debajo de un árbol de mango (2000: 88, 93, 100, $101,110,135)$. Este encuentro la llevaría a escribir al pie del baniano en los días siguientes y de ahí surgiría Canto malabar (1987), casi tan rápido como Play of Consciousness había surgido de la pluma de Muktananda en apenas tres semanas (1994: 419).

Este episodio ilustra el proceso compositivo en la obra de Elsa Cross; si al cierre de su libro previo, Bacantes (1982), escribía que no daría "nombre a tus espumas, / pues los poetas mienten demasiado" (2012: 212), el prólogo que abre Baniano expresa sin rodeos el compromiso irrenunciable de describir la experiencia espiritual, verdadera y quizá por ello inexpresable como hacía su gurú, Swami Muktananda. La evidencia, por supuesto, gravita entre una realidad subjetiva, la de una percepción en ocasiones onírica, y la realidad objetiva. Así, el baniano se vincula desde la realidad subjetiva de Cross con la muerte y transformación de Swami Muktananda, ${ }^{13}$ pero tendrá su correlato en el mundo objetivo cuando, al

13 Escribía Cross en su prólogo: "Yo estaba bajo el baniano cuando lo vi por última vez. Él [Muktananda] pasó de prisa y después ocurrió un fenómeno: todo lo que me rodeaba se transfiguró y tomó su forma. Lo veía en los árboles, en las flores y en las piedras; no sabría explicar cómo lo veía también en los sonidos: tórtolas, y los cantos del templo que se oían hasta allá" (2012: 216). Esta visión debe correlacionarse con las ideas de Muktananda sobre la dispersión del gurú en su mundo, como en los primeros veinte aforismos de su Mukteshwari reunidos bajo el subtítulo de "All is Nityananda" (1995: núms. 1-20; también 2000: 156-158) y en la capacidad del Siddha, el hombre iluminado, para transmitir su Chiti a sus seguidores — Muktananda recoge la anécdota de cuando uno de sus discípulos lavó su baño y quedó extasiado 
final del prólogo (Cross 2012: 217), el árbol sea derribado por un rayo y renazca, como se refleja en otro poema, páginas después:

Estaba junto al baniano aquella tarde en que el zureo de las tórtolas volvía insoportable tanta belleza.

Estaba junto a la estatua de Yama, Señor de la Muerte, montando su búfalo negro mientras Savitri le arrebataba con argumentos la vida de su amado. Tanta belleza a punto de morir. Te vi por última vez allí, desde el baniano. Inmenso como era el viento lo había descuajado y las ramas que cayeron a tierra echaron raíces

(2012: 273).

Para darnos una idea de la forma en la que esta experiencia atraviesa su obra, no olvidemos que en el muy posterior El vino de las cosas, publicado en 2004, este baniano parece transfigurarse en un sabino, que si bien sigue siendo "un árbol partido", ahora es "puerta del inframundo" y recuerda la estrecha relación entre Xibalbá y la ceiba (Cross 2012: 594595); como el baniano, este sabino también forma parte de la experiencia liberadora de la inmortalidad a través de la trascendencia:

Bajo el árbol partido, puerta del inframundo, algo jala al corazón hacia un fondo no alcanzado. [...]

Entre rizos de helecho el tronco del sabino reverdece $y$ en esos musgos del verano que avanza mi muerte acerca sus orillas, duplica tu bella máscara, tu silencio de pájaro.

durante cuatro horas por el contacto con el Chiti que se había concentrado en el agua de la tina (2000: 167). 
Miro en las cosas tus huellas turbulentas

y me hundo en un abrazo

que no quiero dejar

(2012: 594-595).

Resulta difícil, ante este último abrazo, no pensar en la muerte de Swami Muktananda varios años antes, como una "fusión con todas las Cosas". ${ }^{14}$

El inicio de su madurez y plenitud poética en Baniano coincide con una nueva exploración formal. Aunque es posible encontrar de nuevo listados descriptivos basados en la yuxtaposición de los sintagmas, ${ }^{15}$ Cross redirige su poética hacia la imagen como centro de la experimentación (evidente en las secciones finales, "Estancias (canción)" y "Mantra") que desemboca naturalmente en Canto malabar (1987). Ahí, no se lucha ya contra el orden establecido por el lenguaje ni se busca un significante que exprese las tensiones con el logos occidental, sino que se recurre a enunciados complejos (con más componentes, pero al mismo tiempo con una sintaxis solidaria), para dar cuenta de una realidad Ilena de correspondencias entre un plano intelectual (palabras y letras) y otro objetivo dentro de la naturaleza (abejas, semillas, raíces):

Me pronuncias, me dictas,

impones un silencio mentiroso

pues zumban palabras como abejas.

Semillas de fuego entre los labios, letras-raíz,

palabras que oscurecen los objetos que nombran.

14 Quizá sólo para comparar la complejidad asociada a la imagen del árbol en los poemas de madurez de Cross valga la pena recordar un poema temprano de Destiempo, publicado en Espejo al sol en 1989, titulado significativamente "Poema bajo un sauce", donde la pura mención del sauce rememora de inmediato la gran tradición poética mexicana (del "tierno saúz" de Tablada al "sauce de cristal" de Octavio Paz) y en el que las imágenes se acumulan en un registro sostenidamente descriptivo y retórico, entre comparaciones, metáforas y alegorías: "El viento en los follajes / salta como un dios mono, / hace caer los frutos, / hace danzar frenéticas las hojas. // Los árboles se incendian / en rojos y naranjas" (Cross 2012: 110).

15 "Mar de plata viva / ciudad de oro / el rostro de piedra entre el follaje / en su trono se alcanza / pisadas en el aire / pies transparentes" (2012: 238). Véase, al respecto, Dauster (1998: 37). 
Y tú, oh Versado,

diriges el silencio que recorre mi espalda,

aletea en mi garganta,

hace engrosar sílabas mudas que absorben hacia sí

toda esa materia fluctuante

entre nombre y sentido, entre forma y objeto

(Cross 2012: 276).

El verso crece sistemáticamente y los vínculos sintácticos se modulan mediante anáforas recurrentes (tú me pronuncias, tú me dictas, tú me impones) o subordinaciones en distintos niveles (pues, que) para entreverar dos recorridos isotópicos: la voz firme y silenciosa de la divinidad ("Me pronuncias", "me dictas", "diriges el silencio que recorre mi espalda") y el lenguaje imperfecto del ser humano ("zumban palabras como abejas", "Semillas de fuego entre los labios", "letras-raíz", "palabras que obscurecen los objetos que nombran"). La conclusión es fácil de adivinar: la más perfecta expresión es el silencio, esos aleteos en la garganta que se convierten en "sílabas mudas" que como un vórtice atraen a su centro "toda esa materia fluctuante entre nombre y sentido, entre forma y objeto".

En esta etapa, Elsa Cross incluso condesciende a formar secuencias narrativas cortas vinculadas a un tópico concreto (en el ejemplo que sigue, una magistral descripción de la conciencia). El lenguaje dislocado cede su sitio a versículos de sintaxis solidaria de largo aliento y ritmo pausado, donde las imágenes se suceden unas a otras para sugerir una percepción rica, hipersensorial y armónica. Si entre los temas permanece la imperfección enunciativa del lenguaje (las palabras "ruido son, letras locas, silabarios") y la paradójica perfección "al centro del silencio", la enunciación es fluida y regular como ese aliento vital en el cual parece desembocar naturalmente la conciencia. Aunque la yuxtaposición vuelve a estar presente (especialmente en las anáforas y elipsis, como en "soy sólo conciencia", soy "masa de luz", "soy el hueco", soy "espiral del mundo"), la puntuación y la disposición visual del poema los disimulan bien. El uso de sintagmas más amplios y complejos naturalmente requiere más del uso de partículas subordinantes (que): 
Soy sólo conciencia de ti mismo, masa de luz vibrando.

Soy el hueco que tu soplo perfora en el oído, espiral del mundo que se crea allí donde mi nombre que murmuras se abre hacia el espacio, reverbera en una bóveda infinita. Las letras - sólo tu aliento.

Tu aliento, conciencia pura.

[...]

Ocultan las palabras su sentido, ruido son, letras locas, silabarios. ¿Qué soy? ¿Qué eres?

Viento que me tensa como un arco y me dispara al centro del silencioruido de mar, ruido de caracolas.

Y donde pierden alcance los sonidos sólo queda el aliento, la conciencia que oscila: si se acerca a los ojos queda presa en la forma, si se va hacia la luz, inundación...

(2012: 296; 299).

Esta reconciliación con las formas más tradicionales del versolibrismo y el versículo en Baniano se explica dentro del mismo poema: la percepción enriquecida del mundo es un vaciarse de prejuicios ("un hueco: / superficie tocada en la conciencia") y un prescindir de la forma para ceder su lugar a la perfección del aliento como impulso vital:

Una fisura abierta.

El aliento se olvida de sí mismo,

el pensamiento sigue al pensamiento

se detiene,

se desnuda de forma

(2012: 254).

Excepcionalmente, el estilo del poema regresa a la oración simple, unimembre, en versos partidos de sintagmas yuxtapuestos, de su primera etapa; aquí, sin embargo, sirve para subrayar el contraste con la general fluidez discursiva del resto del poemario: 


\section{Luz negra \\ Luz vacía \\ Espacio puro \\ Caracola dormida \\ canta en giros su silencio.

\author{
Punto inmóvil \\ Luz fría \\ Incandescencia \\ Un punto en lo alto
}

(2012: 254; cursivas del original).

Estas series no abundan y más bien sirven para subrayar la solidaridad sintáctica entre las partes como un rasgo de estilo.

Muchos de estos recorridos, de una incipiente narratividad, se articularán alrededor de evocaciones a espacios concretos, como sucede con frecuencia en Jaguar (1990) y Casuarinas (1991), o en Cuaderno de Amorgós (2007); a tal grado que, para Christopher Domínguez Michael, su obra "desde el punto de vista profano y acaso en contra de sus intenciones, también puede ser leída como se lee a los grandes viajeros" (2013: s/p). El punto más alto de su riqueza expresiva Ilegará, paradójicamente, cuando prescinda de la experiencia vital e incursione en un espacio físico que no había visitado; esta no-experiencia o experiencia negativa resulta, por supuesto, explícita a lo largo de Bomarzo (2005):
No fuimos a Bomarzo
sino en el hilo de esas largas conversaciones
que siempre nos llevaban a las mismas fuentes, que pendían de las glicinas de unas pérgolas que quizá nunca existieron en Bomarzo

(2012: 657).

Este poemario marca otro cambio importante en su obra; la solidaridad sintáctica de su estilo y el perfil narrativo de sus poemas se consolida en este nuevo espacio mental, cuyo referente es bien conocido, igual por la 
obra homónima de Mujica Lainez publicada en 1962 que por el mismo jardín construido cerca de Viterbo por Pier Francesco Orsini, pero que Elsa Cross no visitó sino algunos años después de haber escrito el poema (Gómez Estrada 2010). Si la unidad de los poemas anteriores era anecdótica, entre viajes físicos a la India, a Taormina, a la isla de Amorgós, a La Venta, a Chiapas y a Oaxaca, su vinculación a nuevas dimensiones puramente mentales permite enriquecer el plano del significante en el que van a coincidir con fluidez muchas historias diferentes, igual una partida de dados que una incursión ornitológica:

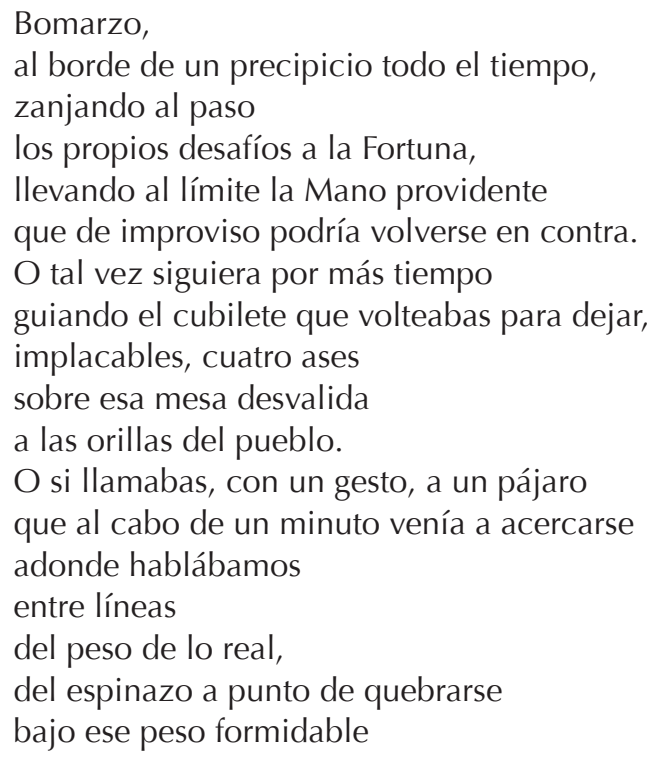

(Cross 2012: 658).

Ahora, el plano del significante sirve para reunir en oraciones largas y de mucha complejidad sintáctica las partes de un rompecabezas de diferentes matices y sintonías. Su fraseo distendido es orgánico, de modo que no distrae de las imágenes más heterogéneas. Si Canto malabar había nacido de la experiencia de sentarse a la sombra del baniano, Bomarzo estaba ligado a cualquier lugar interior y a cualquier tiempo, "como si en la caverna de la mente / aguardaran encuentros no queridos / con viejos rostros de nosotros mismos" (2012: 657). Ya no se internaliza la experien- 
cia del paisaje, sino que la intensidad de su vitalidad interna es la que modela el paisaje, la "turbulencia de adentro" es la que apareja "los ruidos de afuera", deja "sin color al campo", sin flores, sin preguntas, en una secuencia narrativa armónica y fluida:

Un aire de temporal.

Un estruendo aparejando los ruidos de afuera

y la turbulencia de adentro.

No podría sino arrasar con todo

e ir dejando sin color el campo,

sin flor alguna,

sin preguntas,

filtrando por tamices cada vez más delgados

la sustancia bruta de lo vivido

(2012: 676-677).

El baniano de este poemario en las faldas de la mente será un níspero y las preguntas ya no serán sobre la realidad percibida, sino sobre la realidad subjetiva que atraviesa los "tamices cada vez más delgados" del intelecto, donde lícitamente se puede ser y no ser y estar más allá de todo:
Al pie del níspero,
en esa banca que la maleza alcanzaba
rasguñando las piernas,
nos preguntábamos
si en los jardines de Bomarzo
alguien habría hablado así
sobre el ser y el no ser,
sobre aquello que va de uno a otro
y existe más allá del uno y del otro

(2012: 657-658).

En una sola oración compleja, distribuida a lo largo de varios versos de extensión variable, Cross logra integrar un conjunto unitario de estímulos perceptivos en planos distintos: espacial (bajo el níspero, sobre la banca), objetual (banca), natural (níspero, maleza, jardines) y ontológico (el ser y el no ser), todo ello precedido por una conciencia omnisciente ("aquello que va de uno a otro / y existe más allá del uno y del otro"). 


\section{En el centro del poema, el silencio}

Este recorrido puede verse tematizado en una poética lúcida y coherente, compuesta a lo largo de una década, entre 1988 y 1998. Casuarinas o de la percepción (1992), Urracas o de los pensamientos (1995) y Cantáridas o de las palabras (1999) forman, en la Poesía completa de Cross (2012: 473-504), una breve pero intensa trilogía de textos que se publicaron por separado, aunque en fechas próximas y a veces con otras constelaciones poéticas (el caso de Casuarinas, cuya invocación pasó a El vino de las cosas, de 2005, y las secciones "Xibalbá", "Eclipse" y "Zarzas" pasaron a Jaguar y otros poemas, de 2002). Elsa Cross ha cuidado bien que estén unidas en su Poesía completa y su lectura no se interrumpe; por ejemplo, por la publicación de Singladuras, poemas desde la India (1993) o Moira (1993). ${ }^{16}$

"Casuarinas" es un poema divido en 10 cantos que inicia precisamente por negar cualquier posibilidad articulatoria. La percepción se agudiza con la renuncia — afirma Muktananda que "it is certainly true that through renunciation one can find great peace ${ }^{\prime 17}$ (2000: 245):

Te detienes al borde de lo decible.

No hay diferencia entre el cúmulo de palabras

y los labios sellados.

Los ojos giran hacia dentro, todo desaparece-

(Cross 2012: 475).

16 Desde "Todo cede a la luz" (2004), Cross había señalado la unidad de los tres poemas como contraparte de sus poemarios más extensos al estilo de El diván de Ántar y ya los había identificado con los títulos secundarios que atribuirá después: "Junto a poemas como El diván de Ántar — que tendrá sesenta cuartillas, dividido en 25 cantos- he escrito también poemas muy breves. Esto incluye Urracas (1995) y Cantáridas (1999). Este último librito surgió de un viaje a Delfos, y aborda la serpiente délfica y la palabra, mientras que el tema de Urracas son los pensamientos. Un poema anterior, 'Casuarinas' (en el libro con el mismo título), trata sobre la percepción" (Vázquez Valdez 2004: 34).

17 "Es cierto que a través de la renuncia se puede encontrar una gran paz". 
El artificio en este poemario consiste en no mostrar resistencia al lenguaje, en comunicar la experiencia de forma directa, con frases simples y redondas donde incluso el uso de la imagen poética disminuye en favor de una claridad discursiva que no se había alcanzado antes:

Te abres a toda percepción.

Lo que surge, en ti ocurre,

pero no viene de ti.

Tú eres sólo el lugar donde acontece.

En ti el mundo se aniquila.

Y mientras no retraiga sus orillas,

mientras no calcine su simiente entera,

su cambio impredecible,

sigues presa en su juego.

Tus imágenes vuelven a su fuente.

Cada cosa retorna a su elemento,

enmudece, se aquieta,

se deshace.

Dejas ser,

dejas tomar la forma y perderla.

Quedas a solas como el mar en calma

(2012: 478-479).

Para Occidente, la percepción es una vía de conocimiento; para Oriente, se trata de una simple apertura. Como apunta el mismo Muktananda, el cuerpo no es sino el centro de una red de infinitas conexiones. ${ }^{18}$ La percepción del sujeto en estos poemas se da en la integración con lo absoluto y en la desintegración del yo. Se recurre de nuevo al verso partido, pero ahora un verso desemboca en otro para revelar la unidad de los cuatro elementos, donde el mar de agua se prolonga en el de tierra, aire y fuego

18 Véase Play of Consciousness: "the human body may look like a lump of flesh, but that's not really what it is. In fact, it is a wonderful creation, composed of 72 million $n \bar{a} \bar{a}_{\bar{s}}$, or channels. These nādīs, together with the six chakras and the nine openings, form a sort of house" ["el cuerpo humano puede parecer un bulto de carne, pero eso no es realmente lo que es. De hecho, es una creación maravillosa, compuesta de 72 millones de nādīs o canales. Estos nādīs, junto con los seis chakras y las nueve aberturas, forman una especie de casa"] (2000: 33). 
sin solución de continuidad; la percepción del sujeto es una percepción unitaria:

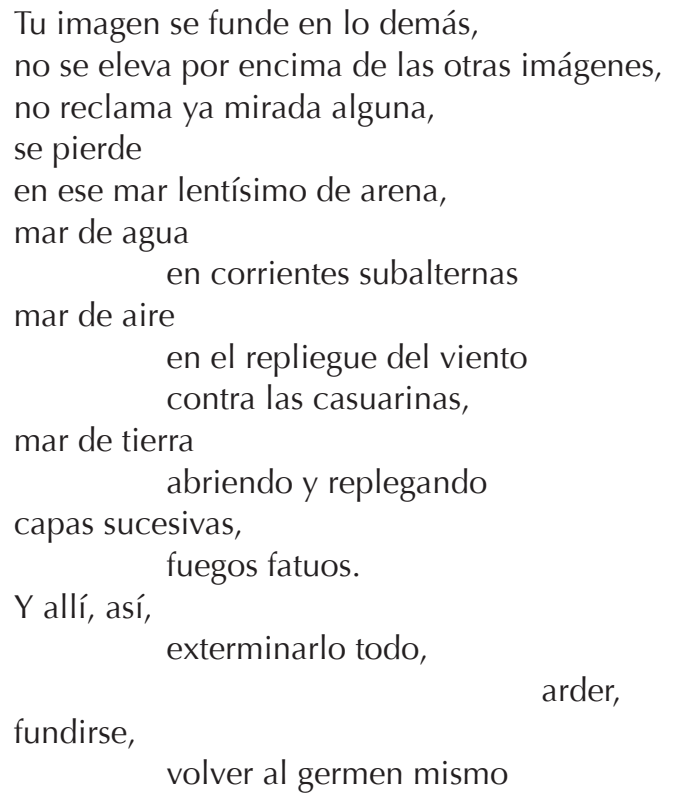

(2012: 479-480).

Cuando la percepción se libera de sus ataduras, la conciencia se ensancha y da cabida a la unidad, donde los opuestos se complementan para llegar a la perfecta geometría de la esfera:

Los sentidos devoran, la mente devora, la conciencia $-y$ de pronto tu mente es una esfera.

Están dentro de ti todas las cosas.

Todo lo abarcas,

lo penetras, lo circundas.

Está la realidad dentro de ti, el mundo mismo, tu propio cuerpo allí, 
visible apenas.

El ojo que mira

contiene el vacío,

es el vacío

y capta al mismo tiempo

el color de las uñas,

los perros ladrando afuera,

la lluvia.

Se adhiere a lo que mira,

toma forma en aquello que contempla

(2012: 484-485).

Fuera de esta percepción omnisciente, todo parece imperfecto. En Urracas o de los pensamientos, Cross desarrolla la alegoría del pájaro-pensamiento indisciplinado que irrumpe en plena meditación ("Las urracas cruzan / el alba pálida de la mente. / Se encienden y se extinguen / en el negro vestíbulo" [2012: 490]) hasta terminar por identificarse con la imperfección del lenguaje ("Como palabras, / oh pertinaces, / cubren lo ya desnudo, / se acumulan / sobre la perfección / de lo no dicho" [493]). Si para Muktananda la meditación perfecta consiste en despejar la mente de pensamientos, ${ }^{19}$ para Cross se centra en liberarla de palabras.

Las cantáridas del siguiente título, pequeños coleópteros de un color verde esmeralda metalizado, muy Ilamativos, terminan convertidas en remanentes secos y muertos de la experiencia vital ("En las ruinas desiertas / secas langostas / cáscaras / escaldaduras / rastros de acíbar / en la lengua" [2012: 497]), quizá para demostrar que la perfección sólo vive en el silencio de la meditación más profunda, exenta de palabras:

Todo desaparece

en una luz adentro

19 Como explica Muktananda: "To free the mind from reflection, from thinking, from memory and knowledge, to make the mind not-mind, is the nature of high meditation. Only saints of the highest caliber know this meditation" ["Liberar la mente de la reflexión, del pensamiento, de la memoria y el conocimiento, para hacer que la mente no sea mente, es la naturaleza de la meditación elevada. Sólo los santos del más alto calibre conocen esta meditación"] (2000: 39). 
el silencio devora las palabras

como insectos pequeños

cantáridas

(2012: 504).

Esta nueva etapa refleja la complejidad de una obra en constante transformación, imposible de agotar en una lectura y con una sola perspectiva, donde la búsqueda formal y la experiencia de la percepción a través de la meditación se alimentan, se aproximan y se distancian para ofrecer al público lector una de las experiencias estéticas más arduas de la poesía mexicana de la segunda mitad del siglo xx; reconocida, sin duda, pero no siempre analizada.

\section{Bibliografía}

Campos, Marco Antonio. "Tres poemas de Elsa Cross". Proceso, 254 (12 de septiembre de 1981): 58. Reseña en línea disponible en: <https://www.proceso. com.mx/131904/tres-poemas-de-elsa-cross> [consultado el 23 de septiembre de 2018].

Castañón, Adolfo. "La aurora perdurable de Elsa Cross", en Elsa Cross, Canto malabar y otros poemas. México: Consejo Nacional para la Cultura y las Artes, 1994. 11-15.

Cross, ElSA. "La dama de la torre", en Revista de Bellas Artes. México, 32 (marzoabril 1970): 94-96.

Cross, ElSA. Poesía completa (1964-2012). México: Fondo de Cultura Económica, 2012.

Cross, Elsa. "El erotismo y lo sagrado en Octavio Paz", en Xicoténcatl Martínez Ruiz y Daffy Rosado Moreno (coords.). Festines y ayunos. Ensayos en homenaje a Octavio Paz (1914-2014). México: Instituto Politécnico Nacional, 2014. $17-26$.

Cross, ElSA. "Impresiones sobre Octavio Paz", en Acuario. Artículos y ensayos sobre creación poética. Xalapa, Ver.: Universidad Veracruzana, 2015a. Ed. digital. s/p.

Cross, Elsa. "Sobre Vislumbres de la India", en Acuario. Artículos y ensayos sobre creación poética. Xalapa, Ver.: Universidad Veracruzana, 2015b. Ed. digital. $\mathrm{s} / \mathrm{p}$.

Cross, ElSA. "El Lejano Oriente en la poesía mexicana", Iberoromania, 87 (2018): 25-35.

Dauster, Frank. "La poesía de Elsa Cross: el círculo de la iluminación", en Revista de Literatura Mexicana Contemporánea. El Paso, Texas, 8 (1998): 37-44. 
Domínguez Michael, Christopher. Diccionario crítico de la literatura mexicana (1955-2011). 2a. ed. corregida y aumentada, 1a. ed. electrónica. México: Fondo de Cultura Económica, 2013.

Estaún Ferrer, Santiago. "Percepción del tiempo y de la causalidad", en Eric Munar, Jaume Roselló y Antonio Sánchez-Cabaco (coords.). Atención y percepción. Madrid: Alianza, 1999. 577-596.

García-Albea, José E. "Algunas notas introductorias al estudio de la percepción", en Eric Munar, Jaume Roselló y Antonio Sánchez-Cabaco (coords.). Atención y percepción. Madrid: Alianza, 1999. 179-200.

Gómez EstradA, Grissel. "Elsa Cross, el origen puede crearse a cada instante" [entrevista a Elsa Cross], en Poesía Digital (septiembre 2010). Entrevista disponible en línea en: <http://www.poesiadigital.es/index.php?cmd=entrevista\&id=63> [consultado el 23 de septiembre de 2018].

Gutiérrez, León Guillermo. "Elsa Cross, creación de la identidad espiritual", Signos Literarios. México, vol. XIII, núm. 26 (julio-diciembre, 2017): 94-109.

Huerta, DAvid. "Nota introductoria", en Elsa Cross. México: Universidad Nacional Autónoma de México, 2012. 4-6 (Col. Material de Lectura. Serie Poesía Moderna, 160).

Huxley, Aldous. Las puertas de la percepción [1954]. Trad. Miguel Hernani. México: De Bolsillo, 2018.

MukTananda, Swami. From the Finite to the Infinite [1a. ed. en inglés, 1989]. Trad. Gurumayi Chidvilasananda New York: SYDA Foundation, 1994.

MukTananda, Swaml. Mukteshwari, Aphorisms [ed. original en hindi, 1969; 1a. ed. en inglés, 1972]. Trad. anónima, con la revisión de George Franklin. Índices y glosario Cynthia Kline, 3a. ed. New York: sYDA Foundation, 1995.

MukTANANDA, Swami. Play of Consciousness, a Spiritual Autobiography [ed. original en hindi, 1970; 1a. ed. en inglés, 1978]. Trad. Gurumayi Chidvilasananda, 3a. ed. New York: SYDA Foundation, 2000.

Paz, Octavio. Obra poética (1935-1988). Barcelona: Seix Barral, 1990.

Paz, Octavio. "Presentación", en Elsa Cross. Miroir au soleil. Trad. Fernand Verhesen. Bruselas: Le Cormier, 1996.

Pollack, Sarah. "Los giros de la espiral: la poética orientalista de Elsa Cross", en Revista de Literatura Mexicana Contemporánea. El Paso, Texas, 48 (2011): 57 67.

TORnERO, ANGÉLICA. "Alquimia para alcanzar el misterio: la poesía de Elsa Cross", en Rogelio Guedea (coord.). Historia crítica de la poesía mexicana, tomo II. México: Fondo de Cultura Económica, 2015. 197-207.

VÁzquez Valdez, María. "Todo cede a la luz" [entrevista a Elsa Cross], en Voces desdobladas / Unfolded Voices. Retratos de mujeres poetas de México y Estados Unidos. México: Universidad Autónoma Metropolitana / Alforja, 2004. 25-61.

Verani, Hugo J. Octavio Paz: el poema como caminata. México: Fondo de Cultura Económica, 2013. 
ALEJANDRO HIGASHI

Es profesor investigador de tiempo completo en la Universidad Autónoma Metropolitana. Unidad Iztapalapa. Ha publicado distintos trabajos sobre literatura mexicana en revistas especializadas, así como Perfiles para una ecdótica nacional. Crítica textual de obras mexicanas. Siglos XIX y XX (UAM / UNAM, 2013) y PM/XXI/360 . Crematística y estética de la poesía mexicana contemporánea en la era de la tradición de la ruptura (UAM / Tirant, 2015). Es miembro de número de la Academia Mexicana de la Lengua y participa en el Seminario de Investigación en Poesía Mexicana Contemporánea. 